\title{
Specific Investigation of Sample Handling Effects on Protease Activities and Absolute Serum Concentrations of Various Putative Peptidome Cancer Biomarkers
}

\author{
Irene van den Broek • Rolf W. Sparidans • \\ Jan H. M. Schellens • Jos H. Beijnen
}

Published online: 30 September 2010

(C) The Author(s) 2010. This article is published with open access at Springerlink.com

\begin{abstract}
Introduction In the search for novel cancer biomarkers, various proteolytically derived peptides have been proposed to exhibit cancer or cancer-type specificity. As these peptides are presumably also generated after sample collection by tumor-specific proteases, extensive investigation of the involved proteolytic processes is crucial for further research.

Materials and Methods Using two previously developed and fully validated liquid-chromatography coupled to tandem-mass spectrometry assays, absolute quantification of, in total, 13 proteolytically derived peptides in human serum was accomplished. The analytes included eight peptides derived from inter- $\alpha$-trypsin inhibitor heavy chain-4 $\left(\mathrm{ITIH}_{4}-30, \mathrm{ITIH}_{4}-29, \mathrm{ITIH}_{4}-28, \mathrm{ITIH}_{4}-27, \mathrm{ITIH}_{4}-\right.$ 26, $\mathrm{ITIH}_{4}-25$, $\mathrm{ITIH}_{4}-22$, and $\mathrm{ITIH}_{4}-21$ ), bradykinin, des$\mathrm{Arg}^{9}$-bradykinin, $\mathrm{Hyp}^{3}$-bradykinin, and fragments from fibrinogen- $\alpha$-chain $\left(\right.$ Fib- $\left.\alpha_{[605-629]}\right)$ and complement component $4 \mathrm{a}\left(\mathrm{C} 4 \mathrm{a}_{[1337-1350]}\right)$. Samples were obtained from different healthy individuals and prepared with variable
\end{abstract}

I. van den Broek $(\varangle) \cdot$ R. W. Sparidans $\cdot$ J. H. M. Schellens

J. H. Beijnen

Department of Pharmaceutical Sciences,

Section of Biomedical Analysis, Division of Drug Toxicology,

Faculty of Science, Utrecht University,

Sorbonnelaan 16 ,

Utrecht 3584 CA, The Netherlands

e-mail: Irene@vandenbroek.net

J. H. M. Schellens

Department of Medical Oncology,

The Netherlands Cancer Institute,

Amsterdam, The Netherlands

J. H. Beijnen

Department of Pharmacy and Pharmacology, Slotervaart Hospital, Amsterdam, The Netherlands tube types, clotting times, and temperatures. Furthermore, stabilities in the serum fraction were assessed and compared to stabilities in serum from breast cancer patients.

Results and Discussion The quantitative analyses showed either increasing or decreasing serum concentrations during blood coagulation, while comparable effects were observed in serum separated from the blood clot. Furthermore, comparisons of inter- and intra-individual variations suggested better reflection of an individual's protease activity after prolonged ex vivo incubation. This was illustrated for the putative breast cancer marker $\mathrm{ITIH}_{4}-22$, revealing better differentiation after incubation of serum at ambient temperature for $24 \mathrm{~h}$.

Conclusion The presented study provides suggestions for more specific and optimized sample preparation, as well as extended knowledge necessary to further explore the opportunities of these proteolytic peptides as cancer biomarkers.

Keywords Biomarker $\cdot$ Cancer $\cdot$ Protease activity $\cdot$ LC-MS/ MS · Peptide $\cdot$ Sample handling

\section{Introduction}

Mass spectrometry-based profiling of the serum proteome is a well-known approach in the search for biomarker proteins able to predict specific cancer types in an early stage $[1,2]$. As a result, also the low molecular weight serum proteome, or peptidome, has attracted increasing attention [3-5], and this has resulted in the proposal of various peptides with putative diagnostic characteristics for different types of cancer in the past years [6-11]. In addition to the classical principle that altered protein levels are directly caused by the cancer type, the upregulated or 
downregulated peptide concentrations have been related to cancer-specific interferences with protein or peptide breakdown pathways [3,5]. Moreover, tumor-specific proteases, including endo- and exopeptidases, have been postulated to contribute to different serum peptidome profiles, also suggesting ex vivo generation of candidate discriminatory peptides after blood collection [10, 12, 13].

This hypothesis has received much criticism. On the one hand, because it is likely to be highly subjected to uncontrollable variables during sample collection, and on the other hand, because of the questionability of the tumor's influence on the ex vivo peptide generation. As this process depends on the activity of coagulation and complement cascades, influences of other factors such as coagulation disturbances or infections are suggested [14-16].

The contribution of various non-cancer-related factors to serum peptidome profiles is widely accepted as a major source of bias and one generally agrees on strict adherence to completely standardized procedures [17-19]. Several studies on the influence of pre-analytical factors on the serum peptidome profile have been performed to further optimize the standardized protocols. Especially the type of blood collection tube, variations in clotting time and temperature, storage conditions, and amount of freezethaw cycles have been investigated and shown to have significant effects on the serum peptidome profile [18-24]. For example, effects of clotting time have been categorized by Umemura et al. [25] as types A, B, or C, in which types $\mathrm{A}$ and $\mathrm{B}$ indicate decreasing and increasing serum concentrations, respectively, with increased clotting time. Type C is defined as showing an initial increase, while remaining relatively stable thereafter.

However, the abovementioned studies on sample handling effects were not quantitative and based on general observations of spectral changes, not providing any specific information on particular peptides. Therefore, to better understand the effects of sample handling variables on the specific expression in serum of putative peptidome markers generated after blood collection, novel quantitative methods will be beneficial.

Two methods using liquid chromatography coupled to tandem mass spectrometry (LC-MS/MS) have previously been developed in our laboratory for the absolute quantification of, in total, 13 putative biomarker peptides in human serum. One method allows simultaneous quantification of eight proteolytic cleavage products of inter-alpha trypsin inhibitor heavy chain $4\left(\mathrm{ITIH}_{4}-30, \mathrm{ITIH}_{4}-29, \mathrm{ITIH}_{4}\right.$ 28, ITIH 4 -27, ITIH 4 -26, ITIH 4 -25, ITIH corresponding with $\mathrm{ITIH}_{4 \text { [658-687] }}-\mathrm{ITIH}_{4}$ [667-687] $[26,27]$, each associated with different types of cancer [7, 9-11]. The other method involves the quantification of bradykinin, Hyp ${ }^{3}$-bradykinin, des-Arg ${ }^{9}$-bradykinin, and fragments of fibrinogen $\alpha$-chain (Fib- $\alpha_{[605-629]}$ ), inter- $\alpha$-trypsin inhib- itor heavy chain 4 ( $\mathrm{ITIH}_{4}$ [666-687] $)$, and complement component $4 \mathrm{a}\left(\mathrm{C} 4 \mathrm{a}_{[1337-1350]}\right)$ [28]. These peptides were all significantly increased in serum from breast cancer patients in the study of Villanueva et al. [10], which could be confirmed for des-Arg ${ }^{9}$-bradykinin and $\mathrm{ITIH}_{4}-22$ after analysis of a large set of clinical serum samples from breast cancer patients and matched controls in our laboratory [29]. In addition, absolute quantification of the eight $\mathrm{ITIH}_{4^{-}}$ derived peptides in a similar sample set revealed statistically significant up-regulation of $\mathrm{ITIH}_{4}-29$ in serum from breast cancer patients [30]. The Fib- $\alpha$ fragment has furthermore been proposed as a marker for HER2-positive breast cancer in another study [8] and as a tumor marker for oral cancer [6]. An overview of the investigated specific proteolytic peptides and their respective amino acid sequence are shown in Table 1.

Now, with the use of these quantitative methods, we specifically investigated the effects of clotting time, the blood collection tube, and clotting temperature on the serum concentrations and stabilities of these peptides. Furthermore, the effects of ex vivo protease activities in serum were compared between several breast cancer patients and controls. Expanded knowledge on the abovementioned effects is required to further explore the biomarker potential of the different peptides for earlycancer diagnosis. For example, little differences in sample handling can be a possible explanation for the observed differences between the study of Villanueva et al. [10] and the recently reported quantitative results $[29,30]$. The specific investigations described here can help in optimizing sample handling protocols for each particular peptide, ideally resulting in (1) the lowest possibility of confounding factors to affect the serum peptide concentration; (2) the highest expression of the peptide formed after proteolytic cleavages; and (3) the most significant differentiation between protease activities in serum from controls and cancer patients.

\section{Materials and Methods}

\section{Blood Collection and Serum Preparation}

Blood was collected at three different locations. At Saltro Diagnostic Center Utrecht (Utrecht, The Netherlands), blood was collected from four healthy individuals in micronized silica-coated plastic (polyethylene terephthalate; PET) tubes from Greiner Bio-One (Alphen a/d Rijn, The Netherlands), either with (4 ml \#454071) or without (4 ml \#454314) an inert olefinoligomer barrier gel. From one of these four individuals, additional blood samples were taken at two other locations with time intervals of ca. 1 month between each occasion of blood collection. In the Utrecht 
Table 1 Amino acid sequences of the investigated proteolytic peptides

\footnotetext{
${ }^{\mathrm{a}}$ Amino acid sequence of precursor proteins derived from NCBI protein database [35]

${ }^{\mathrm{b}}$ Contains a hydroxylated proline amino acid residue, indicated by ${ }^{\circ}$

Fib- $\alpha$ Fibrinogen- $\alpha$ chain;

C4a complement component

4a; $H M W K$ high molecular weight kininogen; ITIH $_{4}$ inter- $\alpha$ trypsin inhibitor heavy chain 4
}

\begin{tabular}{|c|c|c|}
\hline Name & Fragment $^{\text {a }}$ & Amino acid sequence \\
\hline Fib- $\alpha[605-629]$ & Fib- $\alpha_{[605-629]}$ & DEAGSEADHEGTHSTKRGHAKSRPV \\
\hline $\mathrm{C} 4 \mathrm{a}_{[1337-1350]}$ & $\mathrm{C} 4 \mathrm{a}_{[1337-1350]}$ & NGFKSHALQLNNRQ \\
\hline Bradykinin & $\mathrm{HMWK}_{[381-389]}$ & RPPGFSPFR \\
\hline Hyp $^{3}$-Bradykinin & $\mathrm{HMWK}^{\mathrm{b}}[381-389]$ & $\mathrm{RPP}^{\circ} \mathrm{GFSPFR}^{\mathrm{b}}$ \\
\hline Des-Arg ${ }^{9}$-bradykinin & Bradykinin $_{[1-8]}$ & RPPGFSPF \\
\hline $\mathrm{ITIH}_{4}-21$ & $\mathrm{ITIH}_{4}[667-687]$ & SRQLGLPGPPDVPDHAAYHPF \\
\hline $\mathrm{ITIH}_{4}-22$ & $\mathrm{ITIH}_{4[666-687]}$ & SSRQLGLPGPPDVPDHAAYHPF \\
\hline $\mathrm{ITIH}_{4}-25$ & $\mathrm{ITIH}_{4}[663-687]$ & GVLSSRQLGLPGPPDVPDHAAYHPF \\
\hline $\mathrm{ITIH}_{4}-26$ & $\mathrm{ITIH}_{4}[662-687]$ & PGVLSSRQLGLPGPPDVPDHAAYHPF \\
\hline $\mathrm{ITIH}_{4}-27$ & $\mathrm{ITIH}_{4}[661-687]$ & RPGVLSSRQLGLPGPPDVPDHAAYHPF \\
\hline $\mathrm{ITIH}_{4}-28$ & $\mathrm{ITIH}_{4}[660-687]$ & FRPGVLSSRQLGLPGPPDVPDHAAYHPF \\
\hline $\mathrm{ITIH}_{4}-29$ & $\mathrm{ITIH}_{4}[659-687]$ & NFRPGVLSSRQLGLPGPPDVPDHAAYHPF \\
\hline $\mathrm{ITIH}_{4}-30$ & $\mathrm{ITIH}_{4}[658-687]$ & MNFRPGVLSSRQLGLPGPPDVPDHAAYHPF \\
\hline
\end{tabular}

Medical Center (UMC, Utrecht, The Netherlands), plastic (PET) silicone-coated tubes with clot activator (micronized silica particles) and a polymer gel separator from Becton Dickinson (Breda, The Netherlands) were used (Vacutainer $3.5 \mathrm{ml} \mathrm{SST}$ tubes, \#367057). At the third location, Sports Medical Center Papendal (SMCP, Arnhem, The Netherlands), blood was collected in the same plastic tubes with clot activator and gel separator as used at Saltro (Greiner Bio-One; $4 \mathrm{ml} \mathrm{\# 454071).}$

In all cases, blood of each volunteer was collected in seven tubes that contained clot activator and gel separator and were thereafter allowed to clot at room temperature (RT) for $0.5,1$, $2,4,6,8$, or $24 \mathrm{~h}$. From the four individuals, one additional tube with gel separator was allowed to clot for $24 \mathrm{~h}$ at $5^{\circ} \mathrm{C}$, while the two plastic tubes without gel separator were kept either at RT for $1 \mathrm{~h}$ or at $5^{\circ} \mathrm{C}$ for $24 \mathrm{~h}$.

After the specified clotting time, all samples were centrifuged at $1,500 \times \mathrm{g}$ for $10 \mathrm{~min}$ at $23^{\circ} \mathrm{C}$. Subsequently, three $100-\mu 1$ aliquots of serum were taken, while the remaining serum was divided into $500-\mu 1$ portions. All aliquots were immediately stored at $-80^{\circ} \mathrm{C}$ after preparation.

\section{Sample Preparation}

All samples were thawed and further processed on ice. Aliquots of 500 and $100 \mu \mathrm{l}$ were purified by solid-phase extraction on mixed-mode weak cation exchange [28] or silica $\mathrm{C}_{2}$ reversed-phase sorbents [27], respectively.

For assessing the stabilities in serum, $100 \mu \mathrm{l}$ aliquots from the sample with the shortest clotting time (30 min) were left at RT for $0.5,1.5,3.5,5.5,7.5$, and $23.5 \mathrm{~h}$. This was also performed with $500-\mu$ l aliquots of the blood collected at the SMCP from one individual. Furthermore, for all individuals, additional serum aliquots were left at RT for $4 \mathrm{~h}$, using two serum samples from both tube types, with clotting procedures of either $1 \mathrm{~h}$ at RT or $24 \mathrm{~h}$ at $5^{\circ} \mathrm{C}$.

\section{LC-ESI-MS/MS Analysis}

The LC-MS/MS analyses were performed as described in detail previously [27, 28]. Both assays were performed using an Accela high-speed chromatographic system coupled to a TSQ Quantum Ultra triple quadrupole mass spectrometer equipped with a heated electrospray ionization source (all from Thermo Fischer Scientific, San Jose, CA, USA), using multiple reaction monitoring for detection.

For both procedures, calibration standards and quality control (QC) samples were prepared in analyte-free bovine plasma, using stable-isotope labeled peptides or structural analogs as internal standards. Accuracies and precisions of the QC samples were determined to monitor analytical performance, and the quantitative analysis was accepted when deviations from the expected concentrations and variations were below $15 \%$.

\section{Protease Activities in Serum from Breast Cancer Patients}

Serum aliquots of $500 \mu \mathrm{l}$ from nine breast cancer patients, as well as from nine controls were incubated at RT for $24 \mathrm{~h}$, subsequently analyzed by LC-MS/MS to quantify serum levels of the six putative breast cancer marker peptides. Furthermore, $100 \mu \mathrm{l}$ aliquots from 13 different patients and controls were prepared in duplicate to obtain absolute serum concentrations of the eight $\mathrm{ITIH}_{4}$-derived peptides: one aliquot was directly further processed, while the other sample was left at RT for $24 \mathrm{~h}$ before further processing.

All serum samples were obtained uniformly following a strict standardized protocol at two different locations: the Slotervaart Hospital and the Netherlands Cancer Institute/ Antoni van Leeuwenhoek Hospital (both in Amsterdam, The Netherlands) after approval by the local medical ethics committees of both hospitals, and after receiving individuals' written informed consent. The serum samples from 
the breast cancer patients were obtained prior to surgery, and none of them was undergoing treatment. Most breast cancer patients were postmenopausal except for five premenopausal and two menopausal women. The serum samples from the controls (median age 56.1 years; interquartile range (IQR) 46.4-69.5 years) were matched to the serum samples from the breast cancer patients for age (median age 56.2 years; IQR 44.7-69.9 years) and storage duration (median 41 months for both groups).

Blood was collected in $9.5 \mathrm{ml}$ BD Vacutainer ${ }^{\circledR} \mathrm{SST}^{\mathrm{TM}}$ tubes (Beckton-Dickinson) and allowed to clot for exactly $30 \mathrm{~min}$ at $\mathrm{RT}$, after which they were centrifuged at $1,500 \times \mathrm{g}$ for $15 \mathrm{~min}$ at RT and subsequently aliquoted and stored at $-80^{\circ} \mathrm{C}$.

\section{Results and Discussion}

\section{Effect of Clotting Time}

The effects of the clotting time on the serum concentrations of Fib- $\alpha_{[605-629]}, \mathrm{C} 4 \mathrm{a}_{[1337-1350]}$, bradykinin, and des-Arg ${ }^{9}$ bradykinin from healthy individuals are shown in Fig. 1. The Fib- $\alpha_{[605-629]}$ fragment showed increasing concentrations with prolonged clotting time (Fig. 1a) in all individuals. This type B-effect [25] can for Fib- $\alpha$ [605-629] be related to increased breakdown of fibrinogen and fibrinogen-alpha chain during blood coagulation and fibrinolysis [31].

The concentrations of $\mathrm{C} 4 \mathrm{a}$ [1337-1350] were low in all serum samples (max. $2.3 \mathrm{ng} / \mathrm{ml}$ ) and below the lower limit of quantification (LLOQ) for several samples (Fig. 1b). Nevertheless, a small initial increase in the serum concentration could be observed during the first $2 \mathrm{~h}$ of clotting, thereafter slightly decreasing and this type of effect was classified as type C [25]. This effect probably indicates a reduced amount of the founder peptide, i.e., complement component $4 \mathrm{a}$, with $\mathrm{C} 4 \mathrm{a}_{[1337-1350]}$ as an intermediate in further proteolytic processing. Besides the formation of proteolytic cascades, blood clotting can stimulate complement activation, although the exact mechanism of this interplay remains unclear [32]. On the other hand, activation of the complement cascade by blood coagulation can explain the initial increase in the proteolytic fragment of $\mathrm{C} 4 \mathrm{a}$, which is thereafter susceptible to consecutive proteolytic cleavages.

Bradykinin, des-Arg ${ }^{9}$-bradykinin, and Hyp $^{3}$-bradykinin showed rapid decreases with prolonged clotting time (Fig. 1c, d), and maximum serum concentrations were measured in the sample with the shortest clotting time (type A [25]). However, for des-Arg ${ }^{9}$-bradykinin, a C-type initial increase during the first $30 \mathrm{~min}$ can be expected due to proteolytic cleavage of bradykinin. Bradykinin is a key

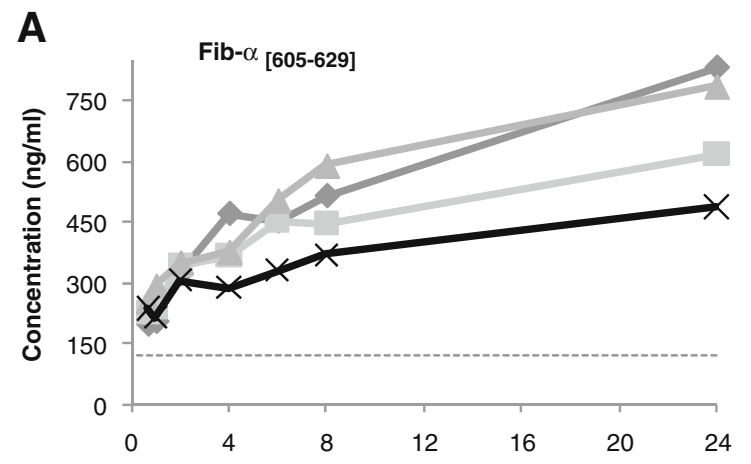

B
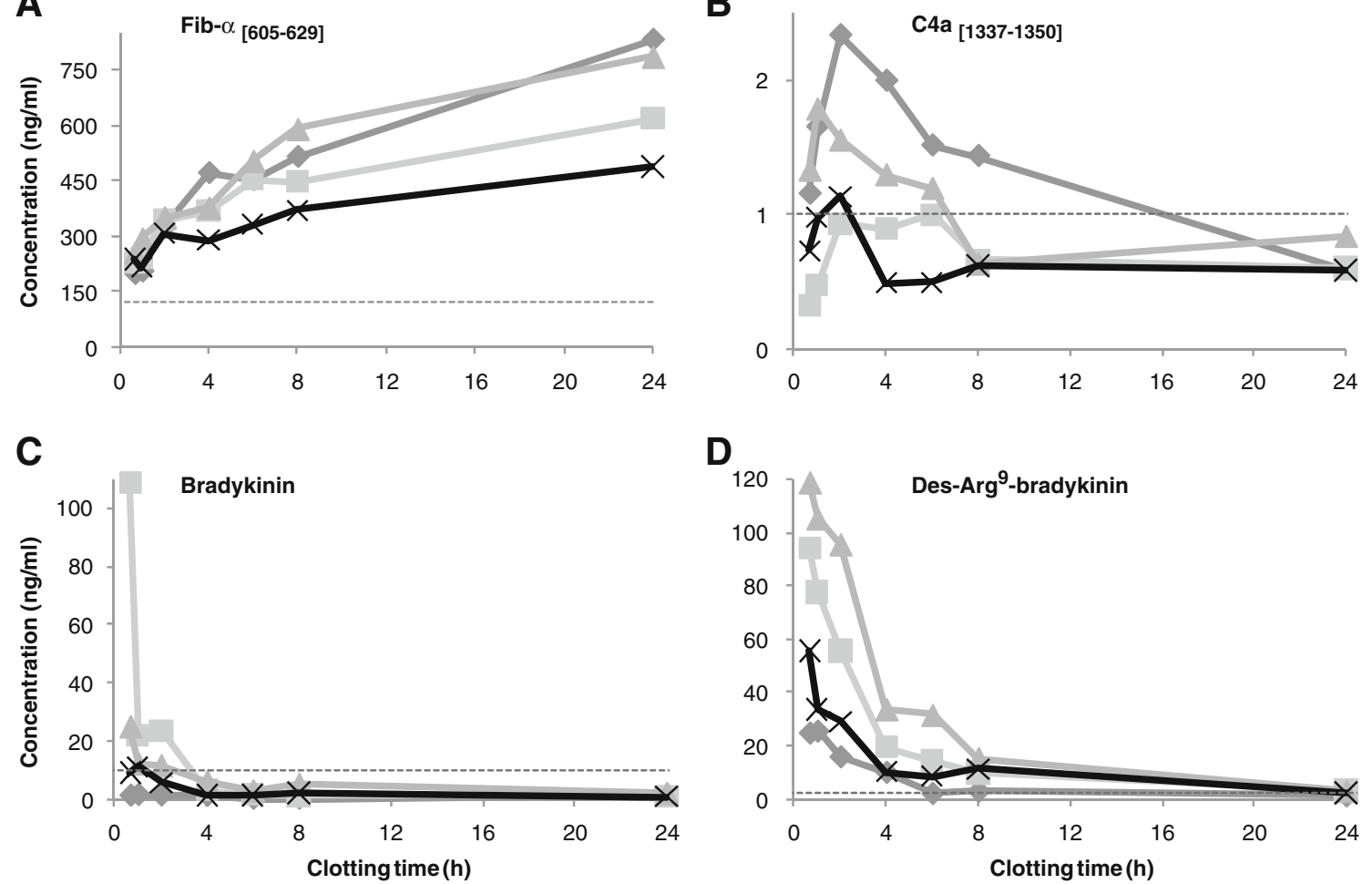

Fig. 1 Effects of clotting time at RT on serum concentrations of a Fib- $\alpha_{[605-629]}$; b C4a ${ }_{[1337-1350]}$; $\mathbf{c}$ bradykinin; and d des-Arg ${ }^{9}$-bradykinin in four healthy individuals (represented by different lines). The dotted line represents the assay's LLOQ 

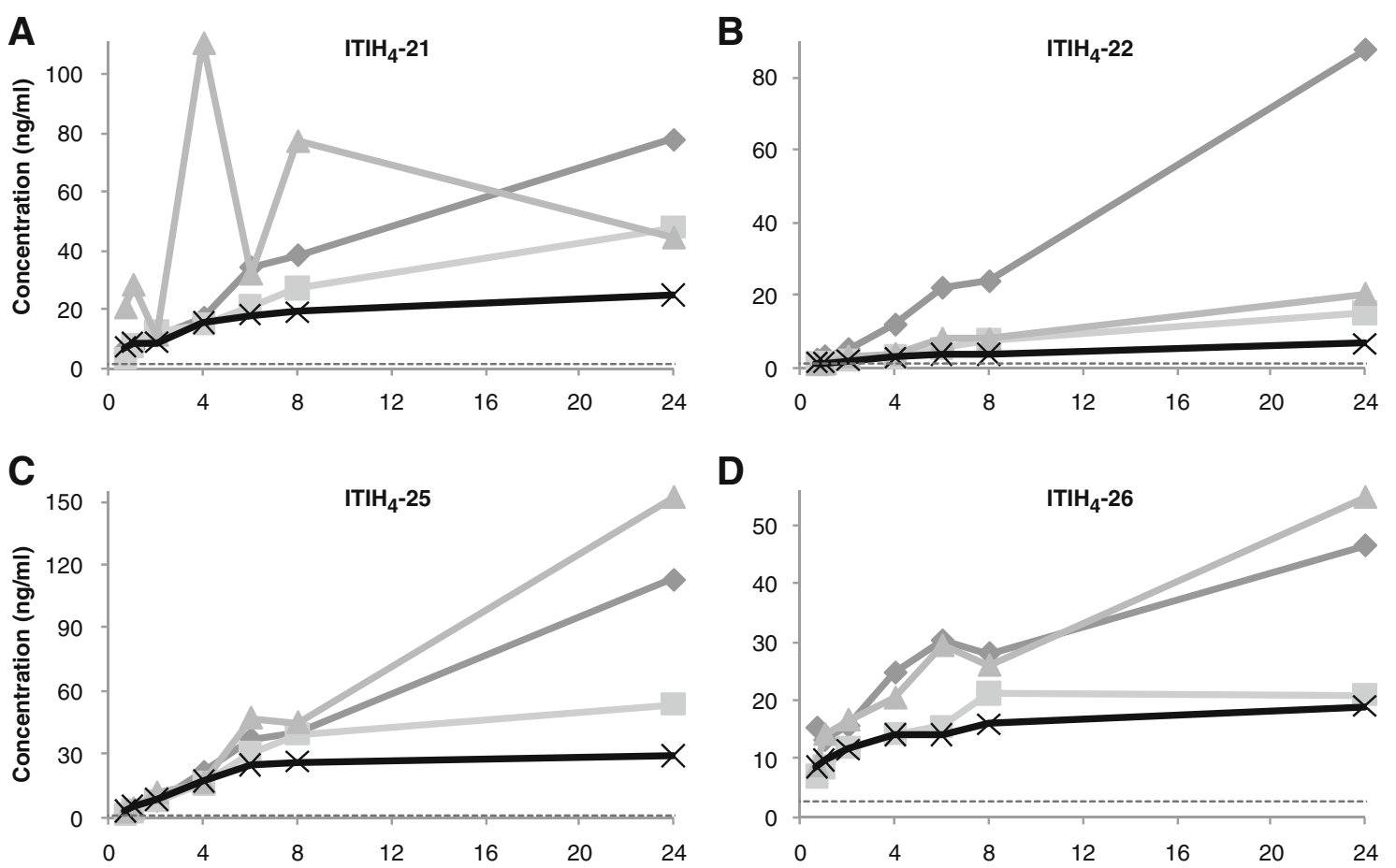

D
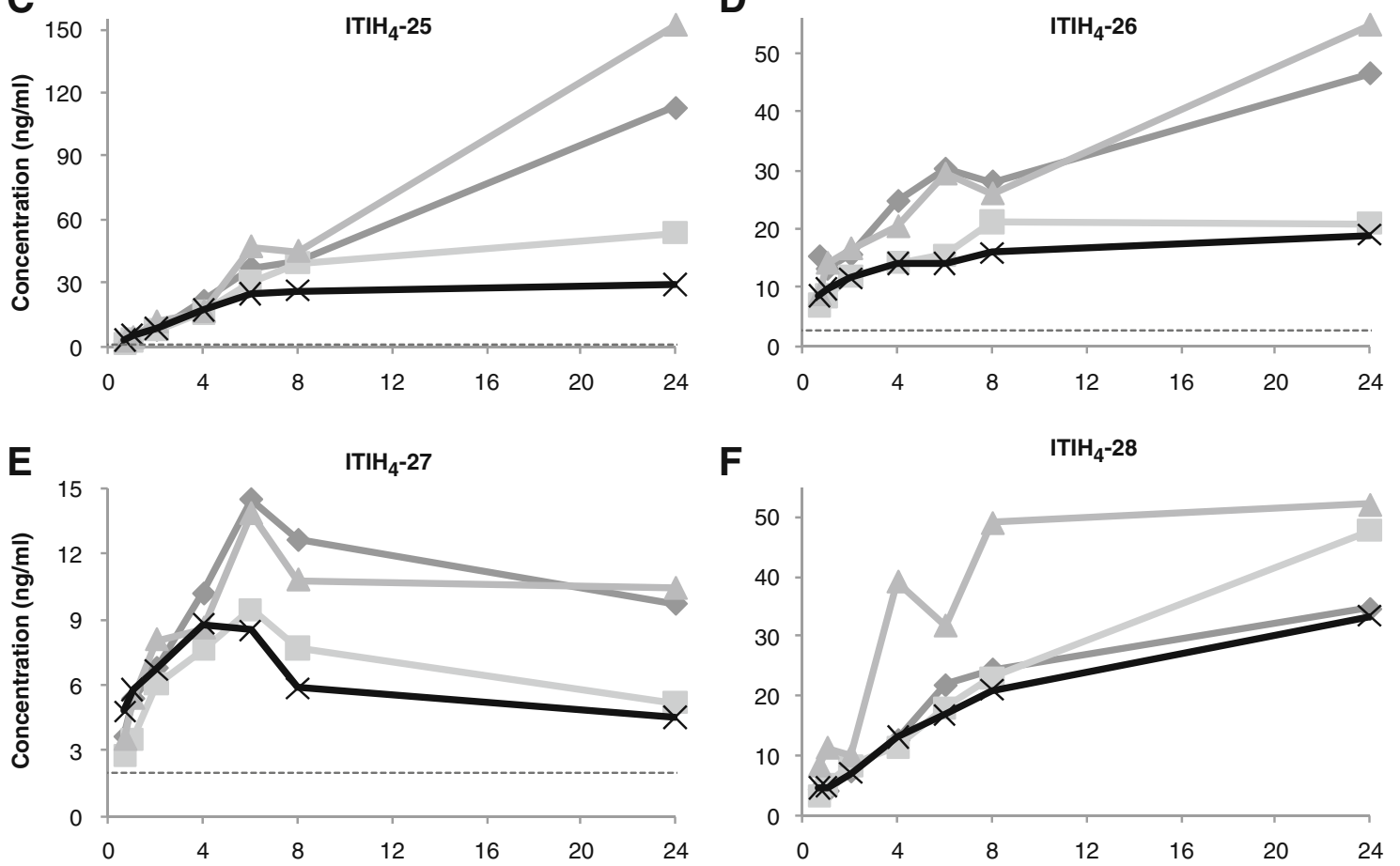

F

$\mathrm{ITIH}_{4}-28$
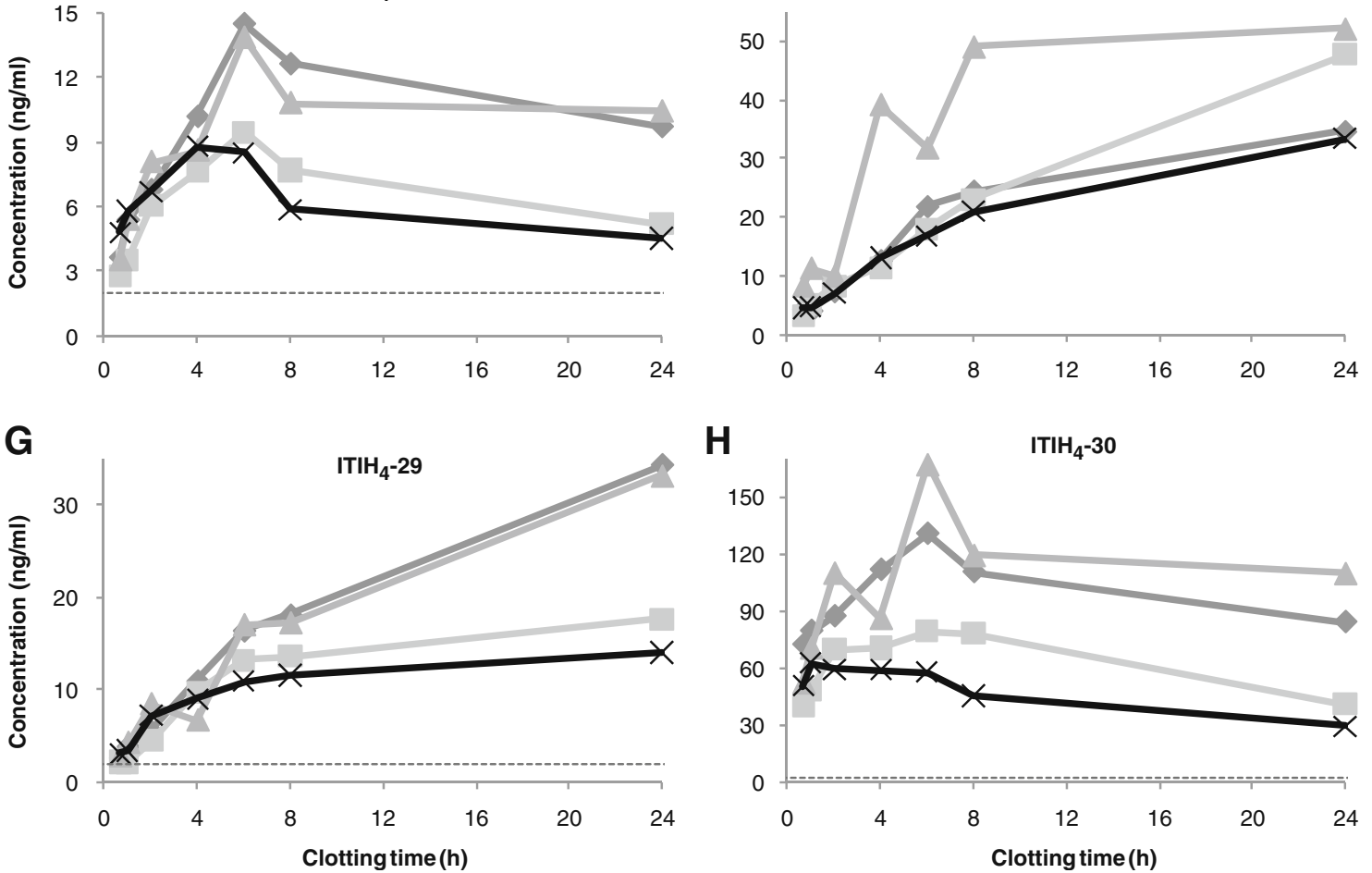

Fig. 2 Effects of clotting time at RT on serum concentrations of a ITIH 4 -21; b ITIH $\mathrm{IT}_{4}-22 ; \mathbf{c} \mathrm{ITIH}_{4}-25 ; \mathbf{d} \mathrm{ITIH}_{4}-26 ; \mathbf{e ~ I T I H} 4-27 ; \mathbf{f} \mathrm{ITIH}_{4}-28 ; \mathbf{g} \mathrm{ITIH}_{4}-29$ and $\mathbf{h} \mathrm{ITIH}_{4}-30$ in four healthy individuals (represented by different lines). The dotted line represents the assay's LLOQ

component in the intrinsic pathway of coagulation as the first step is activation of kallikrein, a serine proteinase which cleaves high molecular weight kininogen and releases bradykinin [31,33]. However, bradykinin is also known to be rapidly degraded ex vivo, for example by carboxypeptidases $\mathrm{N}$ at the $8-9$ position to yield des-Arg ${ }^{9}$-bradykinin. Both bradykinin and des-Arg ${ }^{9}$-bradykinin are predominantly cleaved by angiotensin I converting enzyme at the $7-8$ and 
5-6 positions [34]. The type-A effect for both peptides indicates that bradykinin is generated at the beginning of the ex vivo intrinsic pathway [10] and then rapidly degraded to mainly des-Arg ${ }^{9}$-bradykinin which is thereafter highly susceptible to further proteolytic cleavages.

Clotting time effects on the serum concentrations of the $\mathrm{ITIH}_{4}$-derived peptides are shown in Fig. 2, revealing increasing serum concentrations upon increased clotting time (type B [25]). Only for $\mathrm{ITIH}_{4}-27$ and $\mathrm{ITIH}_{4}-30$ (Fig. 2e, h), decreasing serum concentrations were observed after $\pm 4-6 \mathrm{~h}$ clotting at RT. The effect of clotting time on $\mathrm{ITIH}_{4}-27$ and $\mathrm{ITIH}_{4}-30$ was, therefore, categorized as type $\mathrm{C}$ [25], simply defined in this study as initially increasing, while thereafter decreasing within $6 \mathrm{~h}$ after blood collection. $\mathrm{ITIH}_{4}$ is known to be very sensitive to cleavage by plasma kallikrein [35], followed by trypsin-like cleavages and subsequent terminal truncations by common plasma proteases [36]. The carboxy termini of the $\mathrm{ITIH}_{4}$ fragments measured in this study are identical and consistent with a previously reported cleavage site [37]. The effects of prolonged clotting times on the serum concentrations of these peptide fragments indicate that the peptides are mainly generated ex vivo, with $\mathrm{ITIH}_{4}-27$ and $\mathrm{ITIH}_{4}-30$ as most sensitive to subsequent proteolysis. This is in agreement with previously observed highest susceptibility to degradation of synthetic $\mathrm{ITIH}_{4}-27$ in plasma and serum, thereby apparently generating $\mathrm{ITIH}_{4}-25$ [26].

Although these results show that blood coagulation affects the serum concentrations of all peptides, they cannot be solely attributed to the clotting process. Thorough investigation of the specific role of the involved proteases and the founder peptides as well as their relation with blood coagulation and fibrinolysis is, therefore, required. For example, it remains unclear whether the different extent of the observed effects between the four individuals is caused by the presence of different proteases or by differences in activities of the same combination of proteolytic enzymes.

On the other hand, these results indicate the relevance of adherence to strict standardized protocols as the ongoing proteolytic breakdown in blood during the clotting process easily introduces pre-analytical variance. Furthermore, the protease activities can have completely opposite effects on the various peptides, apparently necessitating different blood collection procedures for the different peptide types. For example, adequate quantification of the $\mathrm{ITIH}_{4}$ peptide fragments in clinical serum samples, with clotting times of exactly $30 \mathrm{~min}$, was seriously complicated by the low expression of these peptides [26, 29]. Prolonged clotting time of the blood samples could be beneficial for more accurate analytical measurements. Contrary, analysis of bradykinin and $\mathrm{Hyp}^{3}$-bradykinin likely requires very short clotting times, although their ex vivo degradation occurs so rapidly that robust serum preparation will still be seriously complicated. Interestingly, $\mathrm{Yi}$ et al. [24] suggest the addition of protease inhibitors prior to blood collection to reduce artificial generation of bradykinin by activation of the kallikrein-kinin system by surface contact with blood collection devices. Nevertheless, as long as the tumor's effect on the endo- and/or exoprotease activity, and thus eventually on the bradykinin serum concentrations, is not elucidated, the most appropriate sample preparation procedures remain speculative.

\section{Effect of Clotting Temperature}

Serum concentrations for the various peptides were compared after clotting of the blood for $24 \mathrm{~h}$ at either RT or $5^{\circ}$ C. Unfortunately, this clotting time was too long to present any results for the rapidly degraded bradykinin and Hyp ${ }^{3}$ bradykinin. Results for the other peptides are presented in Fig. 3, in which the average concentrations after clotting at RT are expressed as $\%$ of the average concentrations measured after clotting at $5^{\circ} \mathrm{C}$. As can be seen in Fig. 3, peptides which are most likely being degraded after $24 \mathrm{~h}$ (type $\mathrm{B} / \mathrm{C}$ ) such as Des-Arg ${ }^{9}$-bradykinin, C4a [1337-1350], $\mathrm{ITIH}_{4}-27$, and $\mathrm{ITIH}_{4}-30$ show higher concentrations in the tubes stored at lower temperature, whereas peptides which are generated along with blood clotting (type A), generally show higher concentrations in the tubes stored at higher temperature. This is not surprising as the protease activities
Fig. 3 Effect of clotting temperature on the serum concentrations of the various peptides, expressed as $\%$ average response after $24 \mathrm{~h}$ clotting at RT compared to $5^{\circ} \mathrm{C}$. Error bars indicate the standard deviation $(n=4)$

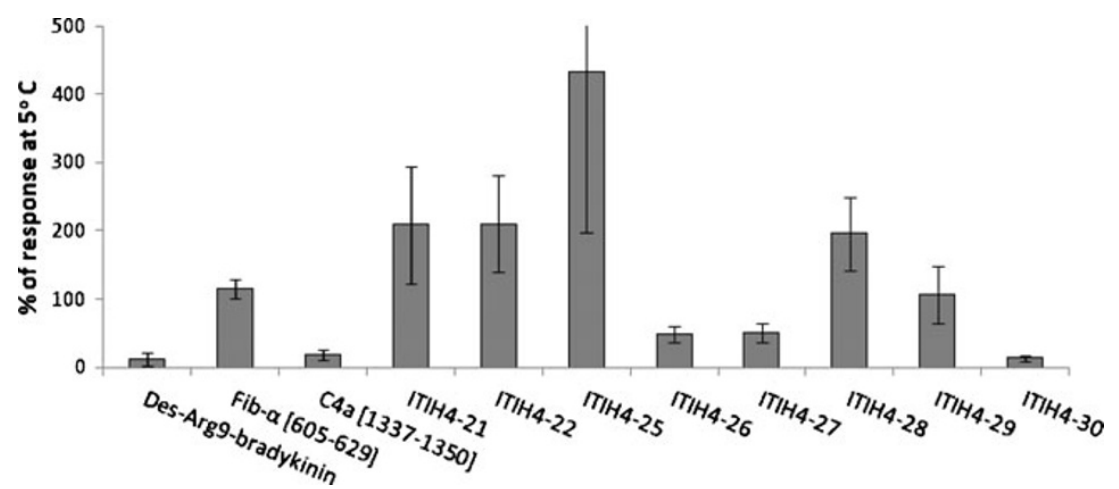




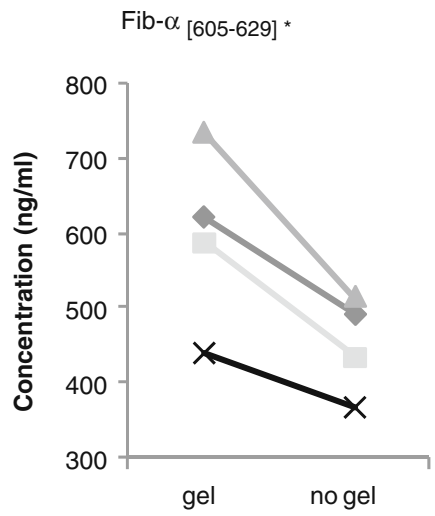

$$
\mathrm{ITIH}-21
$$

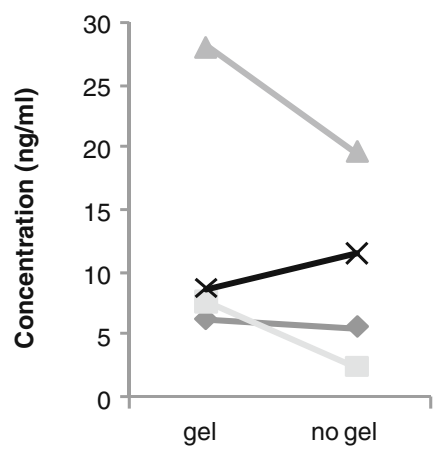

$\mathrm{ITIH}{ }_{4}-27$ *

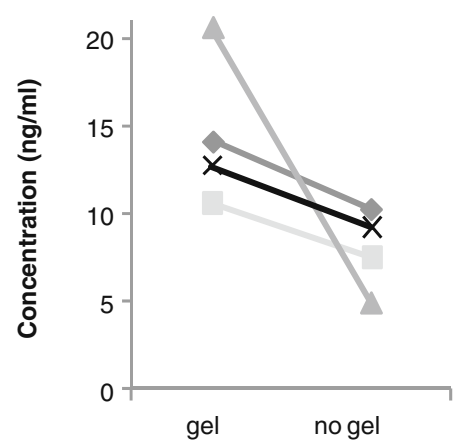

$\mathrm{C} 4 \mathrm{a}_{[1337-1350]}$ *

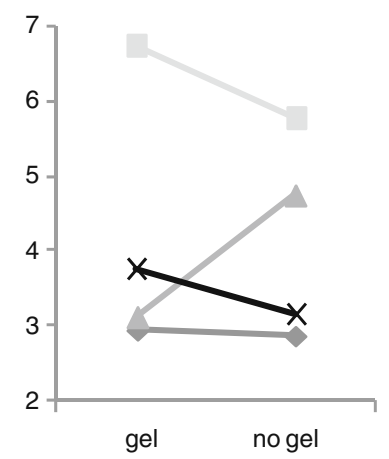

$\mathrm{ITIH}{ }_{4}-22$ *

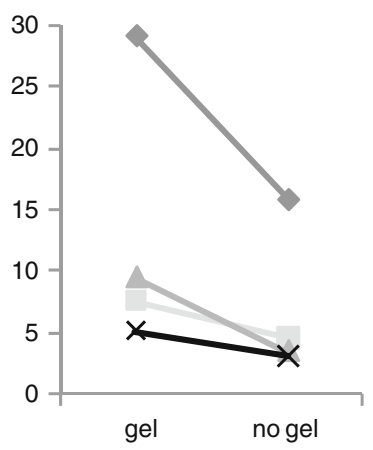

$\mathrm{ITIH}_{4}-28$

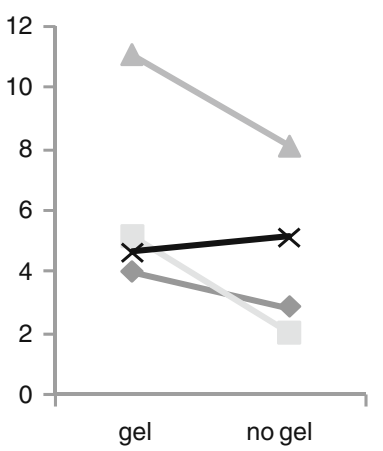

Fig. 4 Measured serum concentrations after blood collection from four healthy individuals (diamonds, squares, triangles, and ex symbols, represented by different lines) in tubes with and without gel

are likely to be lower at lower temperatures. The only exception is $\mathrm{ITIH}_{4}-26$, still showing increasing concentrations after $24 \mathrm{~h}$ clotting at RT, but with higher concentrations when clotting occurred at $5^{\circ} \mathrm{C}$. This once more suggests interference of various specific proteases, either degrading or generating $\mathrm{ITIH}_{4}-26$, with the degrading proteases more specifically inhibited by the lower temperatures. Similarly, $\mathrm{ITIH}_{4}-29$ concentrations appeared more or less unaffected by the clotting temperature, while some of the type-C peptides showed remarkable high concentrations when clotting occurred at $5^{\circ} \mathrm{C}$ (e.g., $4.1 \pm 1.8 \mathrm{ng} / \mathrm{ml}$ for $\mathrm{C} 4 \mathrm{a}$ [1337-1350] and $>10$ times the upper limit of quantification

Bradykinin

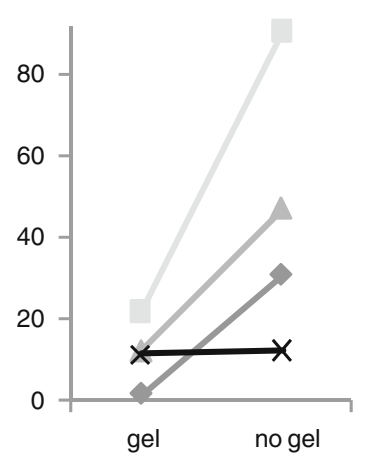

$\mathrm{ITIH}_{4}-25$ *

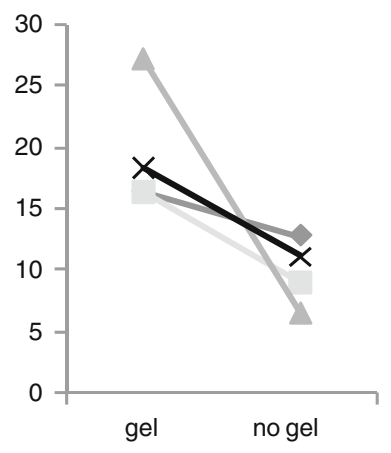

$\mathrm{ITIH} \mathrm{H}_{4}-29$ *

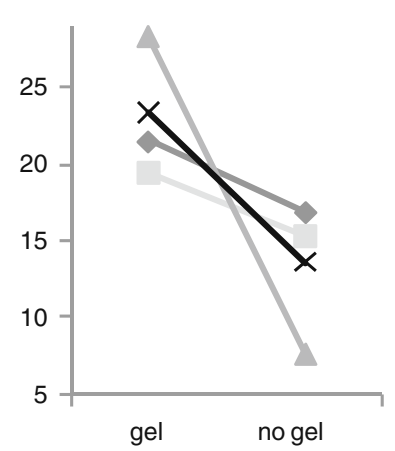

Des-Arg9-bradykinin

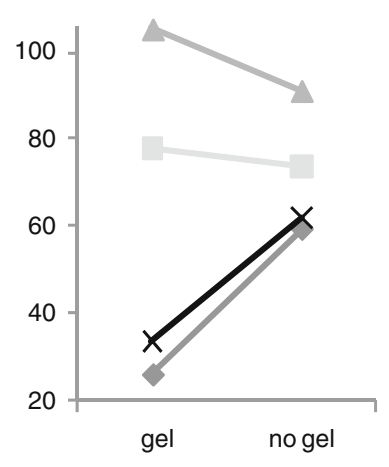

$\mathrm{ITIH}_{4}-26$

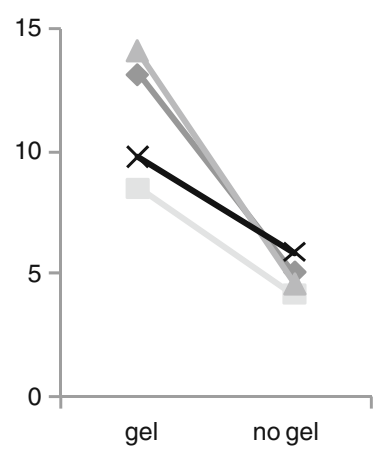

$\mathrm{ITIH}_{4}-30$

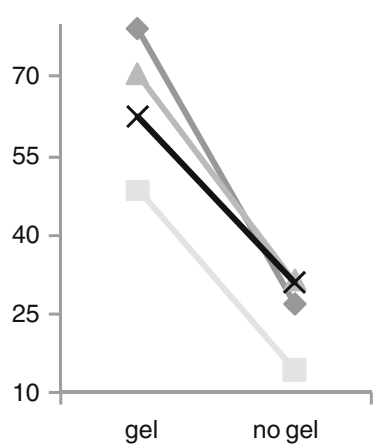

separator for the different peptides. Asterisk indicates clotting time of $24 \mathrm{~h}$ at $5^{\circ} \mathrm{C}$, other samples were allowed to clot for $1 \mathrm{~h}$ at RT

for $\mathrm{ITIH}_{4}-30$ ). This agrees with the suggestion that proteolysis of these peptides is apparently more reduced at lower temperatures than the degradation of their respective founder peptides. Moreover, the mentioned peptides, $\mathrm{C} 4 \mathrm{a}$ [1337-1350], $\mathrm{ITIH}_{4}-26$ and $\mathrm{ITIH}_{4}-30$, are all preceded by an arginine amino acid residue at their $\mathrm{N}$ terminus [38], indicating involvement of the same (trypsin-like) enzyme that is not inhibited by the reduced temperature.

With the observed influence of clotting temperature on the final serum concentrations, careful control and registration of the clotting temperature are required. Additionally, clotting at lowered temperatures can be beneficial to 

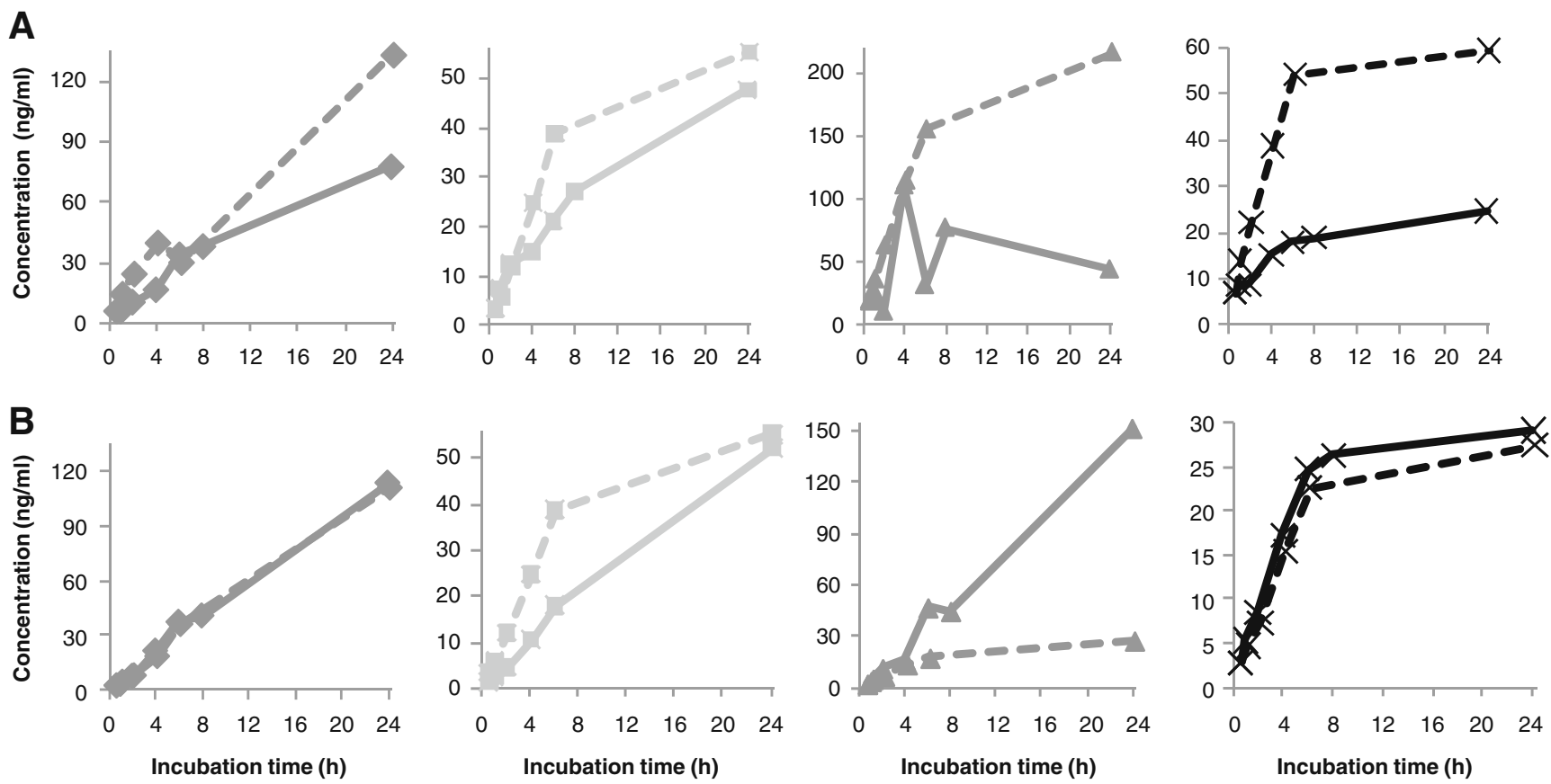

Fig. 5 Comparison between effects of incubation time at RT in serum during blood clotting (straight line) and serum after rapid removal of the blood clot (dotted line) on the absolute serum concentrations of a

$\mathrm{ITIH}_{4}-21$ and b $\mathrm{ITIH}_{4}-25$ in four healthy individuals (diamonds, squares, triangles, and ex symbols)

minimize the effects of small variations in clotting time and/or to provide higher and more accurately measurable concentrations for specific peptides as observed for $\mathrm{C} 4 \mathrm{a}$ [1337-1350] and likely expected for bradykinin peptides.

\section{Effect of Collection Tube}

Two types of silica-coated plastic serum collection tubes were compared. Besides the silica to activate the coagulation process, one tube contained a separation gel in the base of the tube, forming a barrier between serum and blood cells after centrifugation. Figure 4 shows the measured concentrations of the different peptides in serum from four healthy individuals $(\bullet, \mathbf{\square}, \boldsymbol{\Delta}$, and X) after $1 \mathrm{~h}$ clotting at RT in the different tube types (when concentrations were too low after $1 \mathrm{~h}$ clotting, shown results were obtained after $24 \mathrm{~h}$ clotting at $5^{\circ} \mathrm{C}$ ). Besides the effect of the serum collection tube on the measured serum concentration of the different peptides, the separate presentation of the four healthy individuals provides additional insight in the complex formation and degradation processes of the proteolytic peptides.

For most peptides, serum concentrations were higher if prepared in tubes with gel separator (Fig. 4). Only for Atype peptides, with observed ex vivo degradation, lower concentrations were measured, suggesting increased protease activity by the gel. However, C4a $\mathrm{a}_{[1337-1350]}$, des-Arg ${ }^{9}$ bradykinin, $\mathrm{ITIH}_{4}-21$, and $\mathrm{ITIH}_{4}-28$ showed some contrast-

ing results for at least one individual. For C4a ${ }_{[1337-1350]}$, this could possibly be attributed to the absence of the gel barrier between serum and blood clot after centrifugation in one of the tubes $(\boldsymbol{\Delta})$. Des-Arg' ${ }^{9}$-bradykinin on the other hand showed contrasting effects for the samples with a low concentration in the tubes with gel, compared to the samples with a clearly higher concentration, due to higher bradykinin concentrations in these individuals (Fig. 1). Therefore, reduced breakdown of bradykinin in the tubes without gel results in lower concentrations of des-Arg' bradykinin for these individuals compared to the concentrations obtained in tubes with gel separator. In agreement, des-Arg ${ }^{9}$-bradykinin concentrations after $24 \mathrm{~h}$ clotting (not shown) were higher in serum from tubes without gel for all individuals due to the absence of bradykinin and reduced proteolysis of des-Arg ${ }^{9}$-bradykinin in this tube type. The results for $\mathrm{Hyp}^{3}$-bradykinin showed the same pattern as for bradykinin, although lower concentrations were measured (not shown).

Nevertheless, observed deviations for some peptides in one or more healthy individuals suggest possible interference of the gel with peptide's formation, introducing unexplained inter-individual variations. For example, $\mathrm{ITIH}_{4}-21$ showed an opposite (increased) effect for one individual (x) in the tube without gel. Interestingly, for the same individual (x) the increase in $\mathrm{ITIH}_{4}-21$ concentration with prolonged clotting time at RT was less pronounced compared to the other individuals (Fig. 2a), while the increase in serum left at RT 


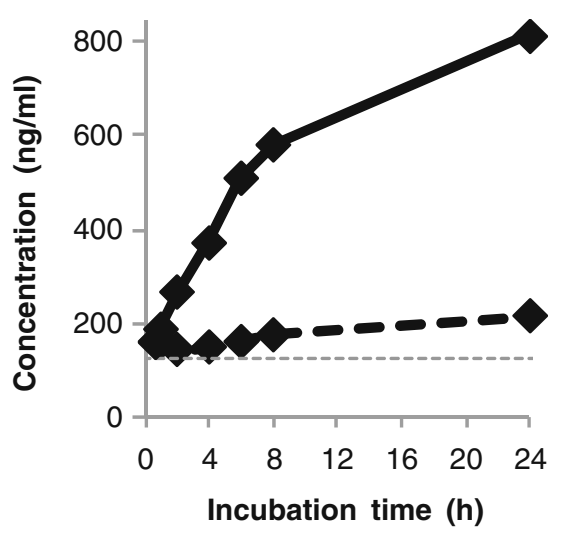

Fig. 6 Comparison between effects of incubation time at RT in serum during blood clotting (straight line) and serum after rapid removal of the blood clot (dotted line) on the absolute serum concentrations of Fib- $\alpha_{[605-629]}$ in one healthy individual

for similar periods of time was remarkably higher for this individual (Fig. 5a). However, as discussed before, the exact mechanism behind the observed different effects between the four individuals remains unclear.

\section{Stability in Serum}

Similar as during the clotting process, continuing protease activities caused alterations in the serum concentrations when serum was left at RT after removal of the blood clot. The $\mathrm{ITIH}_{4}$-derived peptides were measured in serum from which the solid material was removed after clotting for $30 \mathrm{~min}$ and which was subsequently incubated at RT for different periods of time. All peptides showed similar patterns, concerning the changes in serum concentrations, compared to the effect of incubation at RT in the presence of the blood clot, as presented in Figs. 1 and 2. Moreover, for some individuals, identical concentrations were measured in serum left at RT for the same period of time either during or after clotting. Examples of the measured concentrations in serum from healthy individuals with similar incubation times at RT with or without the presence of the solid clot material are shown for $\mathrm{ITIH}_{4}-21$ and $\mathrm{ITIH}_{4}-25$ in Fig. 5.

For Fib- $\alpha$ [605-629], C4a [1337-1350], bradykinin, Hyp ${ }^{3}$ bradykinin, and Des-Arg ${ }^{9}$-bradykinin similar comparisons were performed for only one healthy individual as their quantification required a larger serum volume $(500 \mu \mathrm{l})$. Nevertheless, an indication of the ex vivo stabilities of these peptides in the serum fraction was provided by comparing serum concentrations after incubation at RT for $4 \mathrm{~h}$ to directly analyzed serum concentrations. These measurements showed that Fib- $\alpha{ }_{[605-629]}$ was less obviously generated in serum after removal of the blood clot as during blood clotting, as shown for one individual in Fig. 6. This is not surprising as Fib- $\alpha_{[605-629]}$ is a degradation product of the alpha chain of fibrinogen and is probably generated by plasmin cleavages during the fibrinolysis process in the remaining blood clot [31].

For the other peptides, similar changes in serum concentrations were generally observed for all healthy individuals in the different serum samples after $4 \mathrm{~h}$ incubation at RT as compared to the effects in the presence of the blood clot (Table 2). Nonetheless, Fib- $\alpha_{[605-629]}$ and $\mathrm{ITIH}_{4}-30$ concentrations were lower after $4 \mathrm{~h}$ incubation at $\mathrm{RT}$ in serum preceded by $24 \mathrm{~h}$ clotting at $5^{\circ} \mathrm{C}$ (except for Fib- $\alpha_{[605-629]}$ from tubes with separator gel), in contrast to their increased concentrations in serum preceded by $1 \mathrm{~h}$ clotting (Table 2). Apparently, observed effects merely
Table 2 Average relative changes in serum concentrations after incubation of serum from four healthy individuals for $4 \mathrm{~h}$ at RT

\begin{tabular}{|c|c|c|c|}
\hline \multicolumn{2}{|l|}{ Peptide } & \multicolumn{2}{|c|}{ Relative difference $(\%) \pm$ standard deviation } \\
\hline Serum preparation & Clotting time $(\mathrm{h})$; temperature $\left({ }^{\circ} \mathrm{C}\right)$ & Tube with gel & Tube without gel \\
\hline Fib- $\alpha[605-629]$ & $1 ; \mathrm{RT}$ & $+48.3 \pm 30$ & $+7.4 \pm 8$ \\
\hline Fib- $\alpha[605-629]$ & $24 ; 5$ & $+18.9 \pm 8$ & $-19.0 \pm 12$ \\
\hline $\mathrm{C} 4 \mathrm{a}_{[1337-1350]}$ & $24 ; 5$ & $-54.5 \pm 17$ & $-55.5 \pm 18$ \\
\hline Bradykinin & $1 ; \mathrm{RT}$ & $-64.3 \pm 18$ & $-53.9 \pm 23$ \\
\hline Des-Arg ${ }^{9}$-bradykinin & $24 ; 5$ & $-82.9 \pm 3$ & $-87.1 \pm 5$ \\
\hline $\mathrm{ITIH}_{4}-21$ & $24 ; 5$ & $+151.6 \pm 20$ & $+298.1 \pm 124$ \\
\hline $\mathrm{ITIH}_{4}-22$ & $24 ; 5$ & $+95.3 \pm 40$ & $+75.4 \pm 17$ \\
\hline $\mathrm{ITIH}_{4}-25$ & $24 ; 5$ & $+417.5 \pm 99$ & $+361.7 \pm 108$ \\
\hline $\mathrm{ITIH}_{4}-26$ & $24 ; 5$ & $+35.2 \pm 13$ & $+30.0 \pm 11$ \\
\hline $\mathrm{ITIH}_{4}-27$ & $24 ; 5$ & $+202.5 \pm 43$ & $+139.0 \pm 52$ \\
\hline $\mathrm{ITIH}_{4}-28$ & $24 ; 5$ & $+90.4 \pm 12$ & $+127.7 \pm 42$ \\
\hline $\mathrm{ITIH}_{4}-29$ & $24 ; 5$ & $+109.4 \pm 46$ & $+71.9 \pm 10$ \\
\hline $\mathrm{ITIH}_{4}-30$ & $1 ; \mathrm{RT}$ & $+33.1 \pm 23$ & $+18.8 \pm 14$ \\
\hline $\mathrm{ITIH}_{4}-30$ & $24 ; 5$ & $-10.9 \pm 12$ & $-11.7 \pm 20$ \\
\hline
\end{tabular}



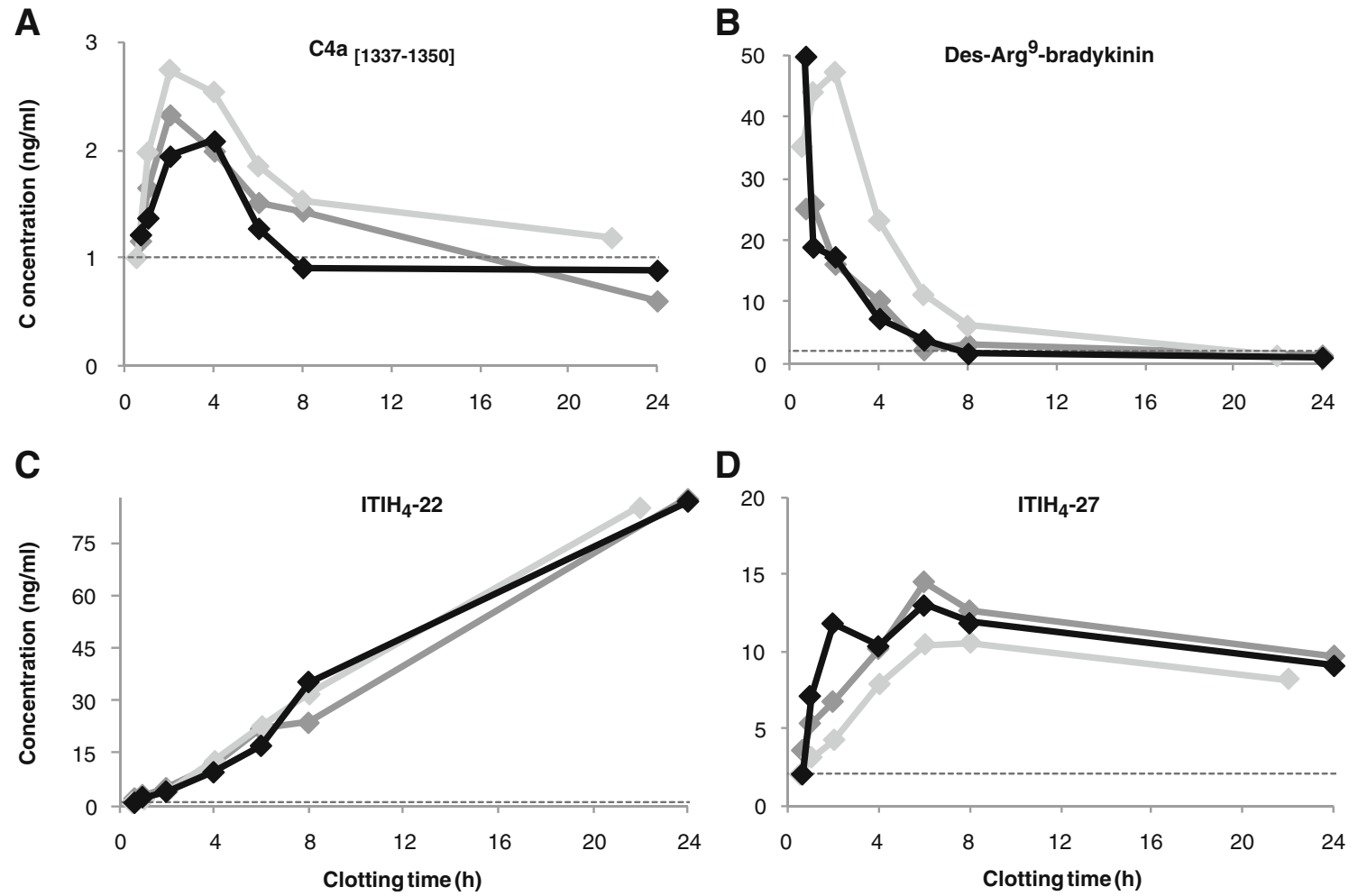

Fig. 7 Examples of intra-individual variations (diamonds) in clotting time effects at RT on the serum concentrations of a C4a ${ }_{[1337-1350]}$, b Des-Arg 9 -bradykinin, $\mathbf{c} \mathrm{ITIH}_{4}-22$ and $\mathbf{d} \mathrm{ITIH}_{4}-27$ in samples collected

on three different days at Saltro (dark-gray), UMC (light-gray) or SMCP (black). The dotted line represents the assay's LLOQ

depend on the amount of the generated, or yet degraded, founder peptides during coagulation than on different protease activities in serum compared to blood during coagulation. Most interesting is the observation of completely identical ex vivo effects in either blood or serum on the concentrations of several peptides in some individuals (Fig. 5). This indicates that for these peptides protease activities are not solely depending on blood coagulation, which is a major argument in questioning putative tumor specificity in ex vivo peptide generation.

Intra- vs. Inter-Individual Variations

As partly discussed above and illustrated in Figs. 1, 2, 3, 4, and 5, large variations in the serum concentrations of the peptides were already observed between four healthy individuals. Lowest inter-individual relative standard deviations (RSD) in samples with the shortest clotting time were observed for Fib- $\alpha_{[605-629]}$ and $\mathrm{ITIH}_{4}-29$ (10.8\% and $14.1 \%$, respectively), while variations were particularly high for bradykinin, des-Arg ${ }^{9}$-bradykinin, and $\mathrm{ITIH}_{4}-28$ (138, 57\% and 44\% RSD, respectively). Additionally, effects of clotting time on the serum concentrations of the various peptides were compared for one individual from whom blood was collected on three different days.
Examples of intra-individual variations in $\mathrm{C} 4 \mathrm{a}$ [1337-1350], des-Arg 9 -bradykinin, $\mathrm{ITIH}_{4}-22$, and $\mathrm{ITIH}_{4}-27$ serum concentrations are presented in Fig. 8.

Interestingly, intra-individual variations were obviously much lower after $24 \mathrm{~h}$ clotting as compared to the interindividual variations for most peptides, especially for the $\mathrm{ITIH}_{4}$-derived peptides (varying from 1.4\% RSD for $\mathrm{ITIH}_{4}$ 22 to $15.0 \%$ RSD for $\left.\mathrm{ITIH}_{4}-28\right)$. This is clearly indicated for $\mathrm{ITIH}_{4}-22$, showing similar high concentrations after $24 \mathrm{~h}$ clotting in one individual (Fig. 7), although $\mathrm{ITIH}_{4}-22$ concentrations were obviously much lower in the other individuals after prolonged clotting (Fig. 2).

These results suggest that prolonged incubation, allowing further proteolytic breakdown, likely increases interindividual variabilities, while reducing intra-individual variations, although observed for only one individual at three different moments. Eventually, prolonged ex vivo processing possibly reduces the effect of confounding factors, providing a better reflection of one individual's endo- and/or exoprotease activity as well as a better differentiation between protease activities in different individuals. However, it is difficult to say whether these variations are wanted (expressing variations in the activity of proteases of interest) or unwanted (caused by factors other than disease-related activities of proteases, e.g., 
Table 3 Measured concentrations of the various peptides in serum from breast cancer (BC) patients and controls (CO) after direct measurement or after $24 \mathrm{~h}$ incubation at RT

\begin{tabular}{|c|c|c|c|c|c|c|c|}
\hline \multirow[b]{3}{*}{ Peptide } & \multirow[b]{3}{*}{$n$} & \multicolumn{3}{|c|}{ Direct measurement } & \multicolumn{3}{|l|}{ After $24 \mathrm{~h}$ at RT } \\
\hline & & \multicolumn{2}{|c|}{ Median concentration [Range ${ }^{\mathrm{a}}(\mathrm{ng} / \mathrm{ml})$} & \multirow[t]{2}{*}{$P$ value $^{\mathrm{c}}$} & \multicolumn{2}{|c|}{ Median concentration $\left[\right.$ Range ${ }^{\mathrm{a}}(\mathrm{ng} / \mathrm{ml})$} & \multirow[t]{2}{*}{$P$ value $^{\mathrm{c}}$} \\
\hline & & $\mathrm{BC}$ & $\mathrm{CO}$ & & $\mathrm{BC}$ & $\mathrm{CO}$ & \\
\hline Fib- $\alpha$ [605-629] & 9 & 157.9 [81-238] & 186.6 [85-493] & .402 & 336.4 [112-423] & $319.4[180-571]$ & .453 \\
\hline $\mathrm{C} 4 \mathrm{a}_{[1337-1350]}$ & 9 & $1.7[0.5-5]$ & $2.2[0.5-8]$ & .251 & $1.7[1-2]$ & $1.3[0.5-3]$ & .566 \\
\hline Bradykinin ${ }^{d}$ & 9 & 94.2 [38-165] & $76.3[57-140]$ & .566 & $35.1[8-102]$ & 38.4 [26-98] & .566 \\
\hline Des-Arg ${ }^{9}$-bradykinin & 9 & 97.6 [69-152] & $87.3[46-168]$ & .402 & $66.3[13-120]$ & $78.9[59-114]$ & .453 \\
\hline $\mathrm{ITIH}_{4}-21$ & 13 & $6.2[1-54]$ & $3.1[1-11]$ & .118 & 40.1 [4-139] & $33.0[1-84]$ & .555 \\
\hline $\mathrm{ITIH}_{4}-22$ & 22 & $1.1^{\mathrm{b}}[1-18]$ & $0.5^{\mathrm{b}}[1-5]$ & .135 & $6.3[1-53]$ & $4.0[1-13]$ & .046 \\
\hline $\mathrm{ITIH}_{4}-25$ & 13 & $2.7[1-22]$ & $1.4[1-2]$ & .061 & $28.3[6-358]$ & $20.8[4-74]$ & .033 \\
\hline $\mathrm{ITIH}_{4}-26$ & 13 & $6.3[2-672]$ & $4.0[1-8]$ & .077 & $14.3[2-605]$ & $8.7[3-44]$ & .144 \\
\hline $\mathrm{ITIH}_{4}-27$ & 13 & $1.7[1-22]$ & $1.0[1-4]$ & .274 & $5.0[1-43]$ & $2.8[1-16]$ & .077 \\
\hline $\mathrm{ITIH}_{4}-28$ & 13 & $4.2[2-50]$ & $2.4[1-7]$ & .061 & $31.2[4-82]$ & $23.6[1-44]$ & .522 \\
\hline $\mathrm{ITIH}_{4}-29$ & 13 & $5.2[1-101]$ & $2.7[1-6]$ & .043 & $25.9[4-306]$ & $13.7[1-58]$ & .043 \\
\hline $\mathrm{ITIH}_{4}-30$ & 13 & $37.2[5-4078]$ & $19.0[3-58]$ & .038 & 33.6 [5-279] & $20.7[6-94]$ & .038 \\
\hline
\end{tabular}

${ }^{a}$ Measurements below the LLOQ are set at 1/2 LLOQ; measurements above the ULQ are presented as the extrapolated value

${ }^{\mathrm{b}}$ Quantified with two methods (13 samples together with the $\mathrm{ITIH}_{4}$-derived peptides and nine with the putative breast cancer markers). All values below $1 \mathrm{ng} / \mathrm{ml}$ were set at $0.5 \mathrm{ng} / \mathrm{ml}$

${ }^{\mathrm{c}}$ Using Mann-Whitney $U$ test. Values in bold indicate $P$ values $<.05$

${ }^{\mathrm{d}}$ Results for bradykinin were similar as for bradykinin, though at lower concentrations and are not presented

coagulation status). Nonetheless, if variations between the four healthy individuals are only caused by haemostatic differences, one would expect similar inter-individual variations for all peptides. This is clearly not the case, e.

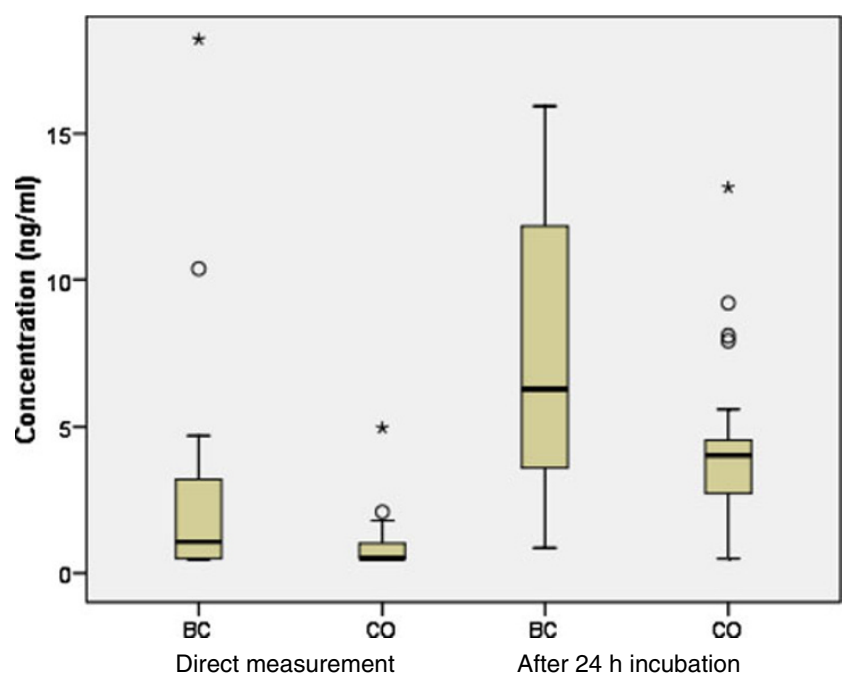

Fig. 8 Box plots indicating the median \pm 25 th percentile (IQR) for $\mathrm{ITIH}_{4}-22$ in serum from breast cancer patients $(\mathrm{BC}, n=22)$ and controls $(\mathrm{CO}, n=22)$ after direct measurement, as well as after incubation of the serum for $24 \mathrm{~h}$ at RT. The lower and upper bars indicate the lowest and highest value within $1.5 \mathrm{IQR}$, respectively, while dots represent values between 1.5-3 IQR (outliers) and asterisks values above 3 IQR (extremes) g., the individual that showed much higher concentrations of $\mathrm{ITIH}_{4}-22$ after prolonged clotting (Fig. 2) than the other individuals, showed more or less similar protease dependent formation of the other $\mathrm{ITIH}_{4}$ fragments. This suggests interferences of more specific proteases than those solely depending on the coagulation and complement activation.

Moreover, the complicated history of the studied peptides is likely to contribute to the observed variations as their formation depends on (1) generation of founder peptides by ex vivo proteolysis, eventually activated during clotting, (2) cleavage of these founder peptides by exo- and or endoproteases, and (3) simultaneous breakdown of the peptide itself.

\section{Comparison Between Breast Cancer Patients and Healthy} Controls

Measured minimum, maximum, and median concentrations of the 13 peptides after direct measurement or $24 \mathrm{~h}$ incubation at RT are presented in Table 3. These measurements were especially intended to investigate the effects of prolonged ex vivo exposure to protease activities on the eventual discriminatory properties of the different peptides in breast cancer. The comparison of absolute serum concentrations to investigate the actual discriminatory properties of $\mathrm{ITIH}_{4}-22$, Fib- $\alpha$ [605-629], C4a [1337-1350], bradykinin, and des-Arg ${ }^{9}$-bradykinin has been described 
earlier in a larger population $(n=62)$ [29]. That measurement revealed that from these peptides, which were all proposed by Villanueva et al. [10] to exhibit putative discriminative properties for breast cancer, only $\mathrm{ITIH}_{4}-22$ and des-Arg ${ }^{9}$-bradykinin showed significantly up-regulated serum concentrations in breast cancer patients [29]. In addition, a similar comparison of absolute serum concentrations of the eight $\mathrm{ITIH}_{4}$-derived peptides recently revealed significant upregulation of particularly $\mathrm{ITIH}_{4}-29$ [30].

Here, comparison of the measured concentrations after direct measurement between the control and breast cancer group, using Mann Whitney $U$ tests, showed statistically significant differences $(P<0.05)$ for $\mathrm{ITIH}_{4}-29$ and $\mathrm{ITIH}_{4}-30$ (Table 3). The differences for these peptides were still significant after $24 \mathrm{~h}$ incubation of the serum at RT, while with these conditions also $\mathrm{ITIH}_{4}-22$ and $\mathrm{ITIH}_{4}-25$ showed significantly upregulated serum concentrations in breast However, the sample size in this study was relatively small and significances only marginal, complicating adequate interpretation of the results. This study does not provide evidence on the existence of differential ex vivo proteolytic processing in breast cancer, which was investigated in more detail in other studies $[29,30]$. On the other hand, prolonged exposure to ex vivo proteolysis appeared effective for improved differentiation between breast cancer and controls for $\mathrm{ITIH}_{4}-22$ and $\mathrm{ITIH}_{4}-29$, visualized in a box plot for $\mathrm{ITIH}_{4}-22$ in Fig. 8. Furthermore, it should be noted that when breast cancer-specific proteases simply have no influence on the generation of these proteolytic peptides, no significant effects after prolonged protease exposure can be expected. For future investigations, prolonged exposure to ex vivo proteolysis might, therefore, be seriously considered.

\section{Conclusions}

Owing to the recent development of two selective and specific LC-MS/MS methods for the absolute quantification of, in total, 13 proteolytic peptides in human serum, it was possible to accurately determine the specific influence of several sample handling variables on the serum concentrations of these putative cancer biomarkers. The results presented in this manuscript show that clotting time, temperature, and type of collection tube drastically affect the final serum concentrations. The different impact of these effects on the various peptides demonstrates the necessity of more specific sample preparation procedures to provide more consistent results and further investigate the large number of proteolytic peptides proposed as putative biomarkers for different types of cancer by various semiquantitative studies. This study, therefore, very well provides suggestions for follow-up investigations to better explore the potential of these peptides as possible biomarkers.

Furthermore, similar ex vivo degradation and/or generation of the various peptides by proteases in serum as during coagulation showed that the protease activities are not solely depending on blood coagulation. This implies that other factors than haemostatic conditions are very likely to contribute to altered protease activities. Moreover, the increased discriminative value of the potential breast cancer marker $\mathrm{ITIH}_{4}-22$ after excessively long exposure to ex vivo proteolysis could support the hypothesis of tumor specific proteases and prolonged incubation of serum samples therefore deserves consideration for future quantitative comparisons of specific peptide fragments.

Ultimately, the presented study provides improved awareness of the pitfalls and opportunities of the low molecular weight peptidome in the search for novel cancer biomarkers.

Acknowledgement We would like to thank all volunteers as well as the assistants at the UMC Utrecht, Saltro Diagnostic Center and SMC Papendal for donation and collection of the blood samples.

Open Access This article is distributed under the terms of the Creative Commons Attribution Noncommercial License which permits any noncommercial use, distribution, and reproduction in any medium, provided the original author(s) and source are credited.

\section{References}

1. Findeisen P, Neumaier M. Mass spectrometry based proteomics profiling as diagnostic tool in oncology: current status and future perspective. Clin Chem Lab Med. 2009;47:666-84.

2. Maurya P, Meleady P, Dowling P, Clynes M. Proteomic approaches for serum biomarker discovery in cancer. Anticancer Res. 2007;27:1247-55.

3. Hu L, Ye M, Zou H. Recent advances in mass spectrometry-based peptidome analysis. Expert Rev Proteomics. 2009;6:433-47.

4. Liotta LA, Petricoin EF. Serum peptidome for cancer detection: spinning biologic trash into diagnostic gold. J Clin Invest. 2006;116:26-30.

5. Petricoin EF, Belluco C, Araujo RP, Liotta LA. The blood peptidome: a higher dimension of information content for cancer biomarker discovery. Nat Rev Cancer. 2006;6:961-7.

6. Cheng AJ, Chen LC, Chien KY, et al. Oral cancer plasma tumor marker identified with bead-based affinity-fractionated proteomic technology. Clin Chem. 2005;51:2236-44.

7. Fung ET, Yip TT, Lomas L, et al. Classification of cancer types by measuring variants of host response proteins using SELDI serum assays. Int J Cancer. 2005;115:783-9.

8. Shi Q, Harris LN, Lu X, et al. Declining plasma fibrinogen alpha fragment identifies HER2-positive breast cancer patients and reverts to normal levels after surgery. J Proteome Res. 2006;5:2947-55.

9. Song J, Patel M, Rosenzweig CN, et al. Quantification of fragments of human serum inter-alpha-trypsin inhibitor heavy chain 4 by a surface-enhanced laser desorption/ionization-based immunoassay. Clin Chem. 2006;52:1045-53. 
10. Villanueva J, Shaffer DR, Philip J, et al. Differential exoprotease activities confer tumor-specific serum peptidome patterns. J Clin Invest. 2006;116:271-84.

11. Zhang Z, Bast Jr RC, Yu Y, et al. Three biomarkers identified from serum proteomic analysis for the detection of early stage ovarian cancer. Cancer Res. 2004;64:5882-90.

12. Koomen JM, Shih LN, Coombes KR, et al. Plasma protein profiling for diagnosis of pancreatic cancer reveals the presence of host response proteins. Clin Cancer Res. 2005;11:1110-18.

13. Peccerella T, Lukan N, Hofheinz R, et al. Endoprotease profiling with double-tagged peptide substrates: a new diagnostic approach in oncology. Clin Chem. 2010;56:272-80.

14. Davis MT, Auger P, Spahr C, Patterson SD. Cancer biomarker discovery via low molecular weight serum proteome profiling where is the tumor? Proteomics Clin Appl. 2007;1:1545-58.

15. Davis MT, Patterson SD. Does the serum peptidome reveal hemostatic dysregulation? Ernst Schering Res Found Workshop 2007:23-44

16. Diamandis EP. Peptidomics for cancer diagnosis: present and future. J Proteome Res. 2006;5:2079-82.

17. Rai AJ, Gelfand CA, Haywood BC, et al. HUPO plasma proteome project specimen collection and handling: towards the standardization of parameters for plasma proteome samples. Proteomics. 2005;5:3262-77.

18. Villanueva J, Philip J, Chaparro CA, et al. Correcting common errors in identifying cancer-specific serum peptide signatures. $\mathrm{J}$ Proteome Res. 2005;4:1060-72.

19. West-Norager M, Kelstrup CD, Schou C, Hogdall EV, Hogdall $\mathrm{CK}$, Heegaard NH. Unravelling in vitro variables of major importance for the outcome of mass spectrometry-based serum proteomics. J Chromatogr B Analyt Technol Biomed Life Sci. 2007;847:30-7.

20. Engwegen JYMN, Alberts M, Knol JC, et al. Influence of variations in sample handling on SELDI-TOF MS serum protein profiles for colorectal cancer. Proteomics Clin Appl. 2008;2:93645.

21. Hsieh SY, Chen RK, Pan YH, Lee HL. Systematical evaluation of the effects of sample collection procedures on low-molecular-weight serum/plasma proteome profiling. Proteomics. 2006;6:3189-98.

22. Timms JF, Arslan-Low E, Gentry-Maharaj A, et al. Preanalytic influence of sample handling on SELDI-TOF serum protein profiles. Clin Chem. 2007;53:645-56.

23. West-Nielsen M, Hogdall EV, Marchiori E, Hogdall CK, Schou C, Heegaard NH. Sample handling for mass spectrometric proteomic investigations of human sera. Anal Chem. 2005;77:5114-23.

24. Yi J, Kim C, Gelfand CA. Inhibition of intrinsic proteolytic activities moderates preanalytical variability and instability of human plasma. J Proteome Res. 2007;6:1768-81.

25. Umemura H, Nezu M, Kodera $Y$, et al. Effects of the time intervals between venipuncture and serum preparation for serum peptidome analysis by matrix-assisted laser desorption/ionization time-of-flight mass spectrometry. Clin Chim Acta. 2009;406:179 80.

26. van den Broek I, Sparidans RW, Schellens JH, Beijnen JH. Liquid chromatography/tandem mass spectrometric method for the quantification of eight proteolytic fragments of ITIH4 with biomarker potential in human plasma and serum. Rapid Commun Mass Spectrom. 2008;22:2915-28.

27. van den Broek I, Sparidans RW, Schellens JH, Beijnen JH. Sensitive liquid chromatography/tandem mass spectrometry assay for absolute quantification of $\mathrm{ITIH}_{4}$-derived putative biomarker peptides in clinical serum samples. Rapid Commun Mass Spectrom. 2010;24:1842-50.

28. van den Broek I, Sparidans RW, Schellens JH, Beijnen JH. Quantitative assay for six potential breast cancer biomarker peptides in human serum by liquid chromatography coupled to tandem mass spectrometry. J Chromatogr B Analyt Technol Biomed Life Sci. 2010;878:590-602.

29. van Winden AWJ, van den Broek I, Gast MCW, et al. Serum degradome markers for the detection of breast cancer. J Proteome Res. 2010;9:3781-8.

30. van den Broek I, Sparidans RW, van Winden AWJ, et al. The absolute quantification of eight inter-alpha-trypsin inhibitor heavy chain $4\left(\mathrm{ITIH}_{4}\right)$-derived peptides in serum from breast cancer patients. Proteomics Clin Appl 2010; in press.

31. Davie EW, Fujikawa K. Basic mechanisms in blood coagulation. Annu Rev Biochem. 1975;44:799-829.

32. Markiewski MM, Nilsson B, Ekdahl KN, Mollnes TE, Lambris JD. Complement and coagulation: strangers or partners in crime? Trends Immunol. 2007;28:184-92.

33. Kaplan AP, Silverberg M. The coagulation-kinin pathway of human plasma. Blood. 1987;70:1-15.

34. Marshall P, Heudi O, McKeown S, Amour A, Abou-Shakra F. Study of bradykinin metabolism in human and rat plasma by liquid chromatography with inductively coupled plasma mass spectrometry and orthogonal acceleration time-of-flight mass spectrometry. Rapid Commun Mass Spectrom. 2002;16:220-8.

35. Nishimura H, Kakizaki I, Muta T, et al. cDNA and deduced amino acid sequence of human PK-120, a plasma kallikrein-sensitive glycoprotein. FEBS Lett. 1995;357:207-11.

36. Koomen JM, Li D, Xiao LC, et al. Direct tandem mass spectrometry reveals limitations in protein profiling experiments for plasma biomarker discovery. J Proteome Res. 2005;4:972-81.

37. Saguchi K, Tobe T, Hashimoto K, et al. Cloning and characterization of cDNA for inter-alpha-trypsin inhibitor family heavy chain-related protein (IHRP), a novel human plasma glycoprotein. J Biochem. 1995; 117:14-8.

38. NCBI: (C4a), NP_002209 (ITIH4), NP_000499 (Fibrinogen- $\alpha$ ), P010422 (HMW kininogen). http://wwwncbinlmnihgov/entrez/ viewerfcgi?val=NP 009224 March 2010. 